\title{
Teachers' Talk about Group Work Assessment before and after Participation in An Intervention
}

\author{
Eva Hammar Chiriac ${ }^{*}$ (D), Karin Forslund Frykedal ${ }^{1,2}$ (10) \\ ${ }^{1}$ Department of Behavioural Sciences and Learning, Linköping University, Linköping, Sweden \\ ${ }^{2}$ Department of Social and Behavioural Studies, University West, Trollhättan, Sweden \\ Email: *eva.hammar.chiriac@liu.se
}

How to cite this paper: Hammar Chiriac, E., \& Forslund Frykedal, K. (2019). Teachers' Talk about Group Work Assessment before and after Participation in An Intervention. Creative Education, 10, 2045-2068. https://doi.org/10.4236/ce.2019.109149

Received: August 16, 2019

Accepted: September 26, 2019

Published: September 29, 2019

Copyright () 2019 by author(s) and Scientific Research Publishing Inc. This work is licensed under the Creative Commons Attribution International License (CC BY 4.0).

http://creativecommons.org/licenses/by/4.0/

\section{c) (†) Open Access}

\begin{abstract}
Previous research has shown that teachers use an indistinct vocabulary, employ few concepts, and expose an embryonic professional language when talking about group work assessment, thus indicating a lack of a professional language. Building on Granström's three different modes of language use everyday, pseudo-meta- and meta-language, the purpose of this article was to examine the teachers' use of languages when talking about group work assessment. Specifically, if and how teachers' use of modes of languages are influenced by them partaking in 1) a study about assessment in group work and 2) in an intervention in form of a short educational session. Data were gathered from interviews with eight teachers working in years five and eight in five Swedish compulsory schools and analysed both qualitatively and quantitatively. The results revealed that all of the teachers use Granstöm's mode of languages to a varying degree when talking about assessment in cooperative situations. A core finding was that intervention in the form of a short education influenced the teachers' way of talking in a positive way. By participating in the intervention, the teachers developed and expanded their mode of language, thereby promoting the use of a common professional language about group work assessment.
\end{abstract}

\section{Keywords}

Group Work Assessment, Classroom Dialogue, Teachers' Talk

\section{Introduction}

Assessment in group work is a highly relevant, but challenging factor when organising group work in an educational setting (Forslund Frykedal \& Hammar 
Chiriac, 2011, 2017, 2018; Hammar Chiriac \& Forslund Frykedal, 2019). Notwithstanding, the scientific support for the interdependence between learning and assessment in previous research (e.g. Black, Harrison, Lee, Marshall, \& Wiliam, 2003; Johnson \& Johnson, 2004; van Aalst, 2013; Wiliam, 2009, 2011; Wiliam \& Thomson, 2007) shows that group work assessment is a neglected research area (Forsell, Forslund Frykedal, \& Hammar Chiriac, 2019). Consequently, there is insufficient theoretical knowledge and/or useful tools for teachers trying to implement well-functioning assessment procedures when using group work. Often group work assessment is described by teachers as a complex and challenging issue (e.g. Forslund Frykedal \& Hammar Chiriac, 2011, 2017; Murray \& Boyd, 2015). Throughout this article, the term "group work assessment" is used as a holistic concept and refers to all the assessment, evaluation, feedback, etc. that is carried out in connection with students' working in groups and which can be expressed in several different ways (see for instance, Forslund Frykedal \& Hammar Chiriac, 2017¹). Group work assessment includes both on-going information gathering with the purpose of supporting students continuous learning (formative assessment) or/and ascertain what students know at a particular time for the purpose of providing grades (summative assessment), on both individual and group level.

Previous research involving Swedish teachers revealed that teachers have problems verbalising and specifying assessment strategies or elucidating the purpose for the various parts of the assessment loop used in everyday practice (Forslund Frykedal \& Hammar Chiriac, 2011, 2017). Teachers use an indistinct vocabulary, employ few concepts, and expose an embryonic professional language when talking about assessment in group work, yielding an amorphous discussion, lacking in precision and clarity, about group work assessment. Further results confirmed by Gillies and Boyle (2010), show that teachers primarily use informal assessment strategies by walking around and observing the students' activities in the classroom. Again, the teachers provided vague descriptions about what they assess, how the assessments are conducted, and use general terms when talking about assessment, hence elucidating the scarcity of languages and/or concepts to talk about assessment in group work. This indicates that one of the teachers' challenges seems to be the lack of a common professional language with useful terminology, models, and concepts when talking about group work assessment.

\subsection{Classroom Dialogue}

Research on the importance of language use in connection with cooperative learning and group work has been focused on languages used in the classroom dialogue (e.g. Gillies, 2014, 2017; Howe, 2014; Mercer \& Dawes, 2014; Rojas-Drummond \& Mercer, 2003) in connection with learning outcomes. This re-

${ }^{1}$ For a more detailed definition of the term group work assessment, see for instance Forslund Frykedal \& Hammar Chiriac (2017) where an empirical grounded theoretical model for aspects to consider when assessing in group work is displayed. 
search shows that teachers play a key role in developing students thinking and learning (Gillies, 2014, 2017) and guide communication in the classroom. Both teacher-student encounters and group work activities are important (Mercer, 2008; Mercer \& Sams, 2006). In keeping with that, Webb and colleagues (Webb, 2009; Webb \& Mastergeorge, 2003; Webb, Franke, Ing, Chan, De, \& Freund, 2008; Webb et al, 2014; Webb, Franke, Ing, Turrou, \& Jonsson, 2015) argue that teachers can use different strategies to encourage students dialogical practice in group work, thus encouraging students to explain, argue, and evaluate their speech. Furthermore, teachers also act as models for students when interacting and talking with them and are thereby able to "teach" students how to talk and reason together to promote learning (Howe, Tolmie, Thurston, Topping, Christie, \& Livingstone, 2007; Mercer \& Howe, 2012; Rojas-Drummond \& Mercer, 2003). Michaels and O'Connor (2015) imply that student learning is improved by academically productive classroom communication. However, for teachers to succeed in classroom dialogue they often require some form of training (Mercer, 2008). Teachers were taught how to develop their language and communication strategies enhanced students' thinking and learning (Gillies, 2017; Gillies \& Khan, 2008, 2009; Mercer \& Sams, 2006). Mercer, Wegerif and Dawes (1999) revealed that teachers who have been trained in using language as a tool to empower student learning manage to improve their students' ability to solve math problems in a better way than students whose teachers have not been trained.

The studies described so far focus primarily on the teacher's role in enhancing the classroom dialogue. A prominent feature embodied in educational research of classroom dialogue is 1) the focus on teacher-student talk and/or studentstudent talk (see e.g. Gillies \& Khan, 2008; Mercer \& Dawes, 2014; Mercer \& Sams, 2006); 2) language as a prime tool for the shared construction of knowledge (Mercer, 2008) and 3) the class as a whole and/or the working groups as the context (Gillies, 2017; Mercer, 2008). However, there seems to be a lack of research on teacher-teacher talk with the aim of making sense of their experience and the development of their pedagogical skills, for instance, group work assessment. Teachers also need to speak with other teachers about the profession and practice creating a common understanding as regards using assessment modes fitting cooperative situations. The importance of having access to a common professional language, theories and/or models concerning group work assessment cannot be neglected (Colnerud \& Granström, 2015).

\subsection{Common Professional Language}

Knowledge of assessment in general (Gillies \& Boyle, 2010; Kuisma, 2007; Zhang, Johnston, \& Bagci Kilic, 2008) and group work assessment in particular (Johnson \& Johnson, 2004) seems to be an unexplored area. Previous research (e.g. Black \& Wiliam, 1998a, 1998b; Black et al., 2003; Johnson \& Johnson, 2004) emphasises a number of concepts and tools important for group work assessment. Research about teachers' professionalism (Colnerud \& Granström, 2015) 
similarly asserts that to be able to communicate and develop their pedagogical practice and competence concerning the language around group work assessment teachers need to develop a common professional language. Lacking knowledge and comprehension of group assessment words and concepts might be one possible explanation for why assessment in groups is a challenge (Forslund Frykedal \& Hammar Chiriac, 2011, 2017). Therefore, if teachers don't have the words to communicate their assessment practices it may be a challenge to know how to assess group work. The importance for teachers to have possibilities to develop their communication skills by education or/and intervention is confirmed in the literature (Mercer, 2008, 2013; Rojas-Drummond \& Mercer, 2003). Teachers' collegial support required to be able to develop their language is also reported (Mercer, 2013).

However, there seems to be a gap between teachers' discussions about assessment and collegial support for developing procedures about assessment in group work (Forslund Frykedal \& Hammar Chiriac, 2011, 2017). In other words, teachers need to have a common language when talking about assessment before they will be able to take advantage of collegial support when developing modes for group work assessment (Colnerud \& Granström, 2015). In this article, we argue that a shared vocabulary and a common academic language could serve as an important tool as well as means for teachers to successfully develop the assessment practice for group work. It is apparent that teachers' discussions with colleagues commonly take place outside the classroom in meetings to discuss, plan or prepare the practice.

\subsection{Modes of Language}

Granström (Colnerud \& Granström, 2015) proposes, based on Keddie's (1984) description of the dissimilarities between "a teacher" and "an educationist", that teachers may use different modes of talking (Colnerud \& Granström, 2015). Granström has identified three different modes of language: everyday language, pseudo-meta-language and meta-language that teachers may use when talking about their educational practice. Hence, the teachers' use of language may pose both opportunities as well as challenges depending on if they "speak the same languages" or not.

In this article, we use Granström's model of modes of language use (Colnerud \& Granström, 2015) to scrutinise teachers' talk about group work assessment (Figure 1).

\begin{tabular}{|c|c|c|}
\hline $\begin{array}{l}\text { Everyday } \\
\text { language }\end{array}$ & $\begin{array}{l}\text { Pseudo-meta- } \\
\text { language }\end{array}$ & $\begin{array}{l}\text { Meta- } \\
\text { language }\end{array}$ \\
\hline
\end{tabular}

Figure 1. Different modes of languages.

The modes of languages may be described in one dimension where everyday language and meta-language represent two opposite poles, while pseudo-meta- 
language is found between the poles. First, we delve into the description of the opposite poles, i.e. everyday language and meta-language, and thereafter the middle alternative, pseudo-meta-language below.

\subsubsection{Everyday Language}

The first mode of languages that teachers may use when talking about assessment in group work is everyday language (Colnerud \& Granström, 2015). It is a direct and concrete language that teachers may use to describe group work assessment in terms of their experiences and actions. Everyday language is based on familiarity rather than grounded in theoretical knowledge and by using everyday language it is possible for teachers to describe assessment accomplished in cooperative situations in relation to what they say and do, but it is insufficient to explain why. Everyday language is a spontaneous and immediate tool that is used for an unreflective talk about assessment in group work and with the help of everyday language it is possible for teachers to express feelings, expectations, and opinions. An everyday language is easily accessible and does not require much consideration and/or reflection. When using everyday language, it is difficult to specify the objectives and purpose of the assessment in cooperative situations and group work assessments are described by external characteristics without any interpretations, explanation, or causal connections (cause and effect).

\subsubsection{Meta-Language}

The mode of language at the opposite side of the pole for teachers to use when talking about group work assessment is meta-language (Colnerud \& Granström, 2015). By means of meta-language it is possible for the teachers to make theoretical descriptions of the practice. It is a language on an explanatory theoretical level that helps the practitioner to transfer practice into theory. In other words, a meta-language may be described as a tool for teachers to communicate, formulate hypotheses, and make models and theories about the professional practice, e.g. assessment modes fitting cooperative situations. With the assistance of a meta-language it is possible to formulate models, mental maps, generalizations and theories of the practice that in turn makes it possible to predict and explain events in educational practice. Further, it is possible, by using metalanguage, to describe the purpose of assessment in group work in relation to the objectives and content in the curriculum, as well as how the group work assessment will be carried out in relation to the knowledge requirements, criteria, goals and abilities. Teachers who use meta-languages could problematise the process, develop assessment practice, and also understand and explain why a certain action is working but not others, hence see and explain the causal relationships.

\subsubsection{Pseudo-Meta-Language}

The third mode of languages, pseudo-meta-language, is found in between the poles (Colnerud \& Granström, 2015). It is a language on an abstract non-theoretical level where teachers use non-contextualised abstract concepts, technical terms and/or 
jargon in order to reduce communication and give instructions. A pseudo-metalanguage is characterised by the use of analytical and abstract assessment concepts just being mentioned in an unreflective way, instead of using them as a basis for analysis or formulating hypotheses explaining causal connections (cause and effects). This is why they use a specific procedure for group work assessment, for example "three stars and a wish", in short, the comrade highlights three things that the other mate has done well and one thing that can be improved. Even if teachers have a certain goal in mind with the assessment in group work using pseudo-meta-language, it does not appear why she/he wants to achieve that goal. Pseudo-meta-language can be described as talking everyday language with great involvement of jargon and technical terms about assessment fitting cooperative situations.

In summary, Granström's model of modes of language use, advocates that teachers can use different modes of languages when talking about assessment in groups. Notwithstanding, teachers need to have access to a professional language to be able to communicate with each other about assessment modes fitting cooperative situations.

\subsection{Intervention Studies}

Previous intervention studies have reported that an educational intervention in educational settings can have positive outcomes in several aspects. Comparing groups who got an intervention with control groups (lacking the intervention) showed that a small education intervention 1) improved pupils efficiency, productivity in group work, and gave the pupils a more positive experience (Ashman \& Gillies, 1997; Gillies \& Ashman, 1996) and 2) facilitated a positive changes in teachers' attitudes towards formative assessment, yielding an improvement in students' achievements (Black, Harrison, Lee, Marshall, \& William, 2003). Interventions studies focusing on employing cooperative learning (CL) have also shown positive outcome such as a) promoting academic knowledge, skills, and understanding (Gillies, 2016; Johnson \& Johnson, 1994, 2002; Slavin, 1989, 1996); b) enhancing students' achievement, socialisation, motivation, and personal development (Roseth, Johnson, \& Johnson, 2008; Slavin, 1989, 1996); and c) increasing cooperative learning achievement compared to individualistic and competitive learning (Johnson et al., 1981; Johnson \& Johnson, 1994, 2002).

In sum, this short outline over intervention studies in an educational context, infer that an intervention could be used as means for improving teachers' professional languages when talking about group work assessment.

\subsection{Purpose}

The overall purpose of this article is to examine teachers' use of languages when talking about group work assessment. Building on Granström's (Colnerud \& Granström, 2015) three different modes of language use: everyday, pseudo-meta-, and meta-language the research question addressed in this article is if and how teachers' use of mode of language are influenced by them partaking in 1) a 
project about group works assessment and in an intervention in the form of short educational sessions or 2) a project about group work assessment (but not in the intervention).

\section{Methods}

\subsection{Context of the Study-A Larger Research Project}

The study presented in this article is part of a larger research project investigating the Assessment of knowledge and skills in group work-an intervention study in everyday classroom practices (Hammar Chiriac \& Forslund Frykedal, 2019). The overarching objective in the research project was to increase knowledge concerning teachers' and students' assessment practices in connection with group work in education. The participants in the research project came from six classes from five different Swedish compulsory schools in different social and geographical areas. In total, 140 pupils from years 5 and 8 and eight teachers were included in the research project. Central to the aims of the research project was an intervention directed at both teachers and students (cf. e.g. Ashman \& Gillies, 1997; Black, Harrison, Lee, Marshall, \& William, 2003; Gillies \& Ashman, 1996; Mercer, 2008; Mercer \& Sams, 2006). The intervention was randomly implemented in all study groups i.e. classes, but two acted as control groups (i.e. did not participate in the intervention during the project). The teacher-focused intervention consisted of education and training on how to work in groups and how to make assessments fitting cooperative situations and were jointly accomplished by teachers and researchers at the university across a two-day period. The first day was devoted to the theoretical aspects of the role of a teacher; tasks regarding group work and group work assessments were two vital aspects that were problematized. The second day was more of an "applied workshop day"; where together the teachers produced common materials for the forthcoming group work. The teachers belonging to the control groups received the same training after the project was completed. The intervention for the students addressed topics such as how to work in groups and consisted of a two-hour lecture/workshop led by the researchers. Thereafter the classes-whether they received an intervention or not-worked for 3 - 6 weeks on the same mathematics-related group task. To be able to answer the aim of the research project, a mixed-method approach was employed, and data collection was implemented numerous times during the project. Both qualitative and quantitative data were collected and likewise analysed both qualitatively and quantitatively. The qualitative data were collected through interviews and observations, while the quantitative data were gathered through questionnaires and observations. For more information on the design and implementation of the research project, see Hammar Chiriac and Forslund Frykedal (2019).

\subsection{Focus and Participants in This Study}

As the focus of this study rested on if and how teachers talk about group work 
assessments were influenced by them partaking in the study, a rather narrow set of data was available. The data in focus here were gathered from individual interviews with the eight teachers working in the participating classes. Hence, the rationale for focusing on a very small group of participants in this particular study was that they were equivalent to the total group of teachers interviewed. The informants were six female and two male teachers 34 - 48 years old (mean 43 years old), with 9 - 23 years of experience (mean 16 years) working as teachers in mathematics.

\subsection{Data Collection}

14 semi-structured individual interviews lasting between 30 - 60 minutes (mean 42 minutes) resulting in a data corpus of 590 minutes in total were conducted (Table 1). Half of the interviews were accomplished as the first event in the study and lasted 33 - 46 minutes (in total 284 minutes). The other half of the interviews were accomplished as the last occurrence in the study and lasted $30-60$ minutes (in total 306 minutes). An interview guide with open questions was used to cover the topics group work and groupwork assessment (see Appendix 1). By using open questions, the teachers were able to talk about group work and group work assessment using their own languages (i.e. terminology, models and concepts). The flexibility of the interview process enabled us pick up on the vocabulary used by the teachers and permitted an interactive discussion, thus capturing teachers' talk about group work assessment.

Due to technical failure and requirements in the field six teachers were interviewed both before and after partaking in the study, while one teacher was only interviewed before and the other teacher was interviewed only after the study. Apart from participating in the study all teachers except two (who acted as control group) also took part in the intervention.Thus, the teachers were active participants in the intervention in cooperation with each other and the researchers. The teachers in the control groups received the same training after the data collection was completed.

Consequently, this means that interviews with seven teachers who were about to participate in the study, and interviews with seven teachers who have participated in the study comprise data corpus in the study.

\subsection{Analyses}

In order to capture the teachers' use of mode of language when talking about

Table 1. Elucidatory description of interviews.

\begin{tabular}{llllll}
\hline $\begin{array}{l}\text { The time of the } \\
\text { interviews }\end{array}$ & $\begin{array}{l}\text { Number of } \\
\text { teachers }\end{array}$ & $\begin{array}{l}\text { Number of } \\
\text { interviews }\end{array}$ & $\begin{array}{l}\text { Total } \\
(\mathrm{min})\end{array}$ & $\begin{array}{l}\text { Shortest - longest } \\
(\mathrm{min})\end{array}$ & $\begin{array}{l}\text { Mean } \\
(\mathrm{min})\end{array}$ \\
\hline $\begin{array}{l}\text { Before and after } \\
\text { Before }\end{array}$ & 8 & 14 & 590 & $30-60$ & 42 \\
After & 7 & 7 & 284 & $33-46$ & 41 \\
\hline
\end{tabular}


group work assessment and if and how their use of languages was influenced by them participating in this study, both qualitative and quantitative analyses were necessary.

\subsubsection{Qualitative Analyses}

A qualitative deductive content analysis was used (Elo \& Kyngäs, 2008). The process began with a familiarisation of the informants' responses, which were transcribed, anonymised and imported into the qualitative analysis program MAXQDA 12. Then the qualitative analyses were performed in two waves, each including several phases.

The first wave included a deductive content analysis identifying and extracting text units where teachers talked about assessment (Elo \& Kyngäs, 2008; Hsieh \& Shannon, 2005). A holistic approach was employed by including all text units where any type of "assessment" (i.e. not only about group work assessment) could be identified, for instance statements on feedback, evaluation, estimation and/or appraisements were also included. The analysis was not limited to the questions focusing on assessing in group work, since all the questions in preand post-interviews were included. This part of the analysis was first conducted by the two authors separately, and second discussed jointly.

The text units extracted were different in length and the shortest consisted of a few words e.g. "Exciting with assessment" or "Yes, individual assessments as well", but these shorter units occurred rarely in this part of the analysis. More frequent were longer text units, and some units were even composed as a whole paragraph. The decision for the demarcation was that each text unit consisted of a coherent text unity. The excerpt below is a typical example of an assessment text unit.

Yes, exactly so. Thus, because there will be someone who will be good in the group, so I said, but the group will get a grade on these two questions, you will get a group grade, and then everyone in the group will get the same grade. Then, of course, I will assess you individually as well, because I will walk around and watch during the lessons. We have six lessons that you will work in and I cannot keep my eyes shut during six lessons. They just say, no, it's clear. Certainly, this is about being clear enough concerning what you want, what you are assessing. To us teachers it is obvious, we know yes, but this is what I'm looking at. This is what I assess. But for the students, it is hard to know because they are having trouble for the matrixes as well (Teacher Year 8).

These text units jointly became the unit of analysis (Graneheim \& Lundman, 2004) for the second wave of the qualitative analysis.

The second wave also consisted of a deductive content analysis (Elo \& Kyngäs, 2008; Hsieh \& Shannon, 2005; Marshall \& Rossman, 2015) as we wanted to test if and how the units of analysis fit the prerequisites of Granstöm's model of mode of languages (Colnerud \& Granström, 2015). First, a key issue was to develop a robust structured categorization matrix (Elo \& Kyngäs, 2008) based on Granström's 


\begin{tabular}{|c|c|c|c|c|}
\hline $\begin{array}{l}\text { Mode of } \\
\text { language }\end{array}$ & Everyday language & \multicolumn{2}{|c|}{ Pseudo-menta-language } & Meta-language \\
\hline $\begin{array}{l}\text { Level of } \\
\text { language }\end{array}$ & $\begin{array}{l}\text { Concrete action } \\
\text { Unreflected } \\
\text { Familiarity } \\
\text { Expression of feelings, } \\
\text { opinions and expectations }\end{array}$ & \multicolumn{2}{|c|}{$\begin{array}{l}\text { Abstract, non-theoretical } \\
\text { Pre-scientific } \\
\text { Assessment concepts used } \\
\text { unreflective, e.g. as repetition or } \\
\text { "taken for granted" }\end{array}$} & $\begin{array}{l}\text { Explanatory and theoretical } \\
\text { Reflected and analytical } \\
\text { Transfer practice to theory }\end{array}$ \\
\hline Characteristics & $\begin{array}{l}\text { Spontaneous and } \\
\text { unreflective language } \\
\text { used to describe /talk about } \\
\text { assessment in } \\
\text { the classroom }\end{array}$ & \multicolumn{2}{|c|}{$\begin{array}{l}\text { Use technical terms and/or jargon } \\
\text { in order to reduce communication } \\
\text { and give instructions }\end{array}$} & $\begin{array}{l}\text { Language as a tool for } \\
\text { investigating and/or } \\
\text { highlighting causal } \\
\text { relationships and } \\
\text { consequences }\end{array}$ \\
\hline $\begin{array}{l}\text { Assessment } \\
\text { practice }\end{array}$ & $\begin{array}{l}\text { Put plans into practice } \\
\text { Perform assessments as } \\
\text { instructed by the teacher }\end{array}$ & \multicolumn{2}{|c|}{$\begin{array}{l}\text { Want to reach a certain goal with } \\
\text { the assessment, but does not } \\
\text { elucidate why } \\
\text { (E.g. using "three stars and a } \\
\text { wish" without problematise way) }\end{array}$} & $\begin{array}{l}\text { What should be assessed in } \\
\text { relation to the curriculum } \\
\text { objectives and content } \\
\text { (knowledge requirements, } \\
\text { criteria, abilities) }\end{array}$ \\
\hline Keywords & $\begin{array}{l}\text { Concrete concepts } \\
\text { Feelings } \\
\text { Experience }\end{array}$ & \multicolumn{2}{|c|}{$\begin{array}{l}\text { Abstract concepts } \\
\text { Denominations without causal } \\
\text { connections }\end{array}$} & $\begin{array}{l}\text { Theories } \\
\text { Models } \\
\text { Generalizations } \\
\text { Causal relations }\end{array}$ \\
\hline Threshold & \multicolumn{2}{|c|}{$\begin{array}{l}\text { Knowledge of and use } \\
\text { assessment concepts, } \\
\text { jargon and technical terms }\end{array}$} & \multicolumn{2}{|c|}{$\begin{array}{l}\text { Causal connections } \\
\text { Consequences (understand and explain way } \\
\text { certain assessment work and others don't.) } \\
\text { Draw conclusions }\end{array}$} \\
\hline
\end{tabular}

Figure 2. Categorization matrix.

model of mode of languages (Colnerud \& Granström, 2015). As this model not had been elaborated before, an operationalization of the model was compiled into a categorization matrix (Figure 2). This brought some issues, such as: What are the significant dissimilarities between the different modes of languages proposed in the model? What are the characteristic features for each mode of languages that point to teachers' use of that particular mode, etc. With the support of Glasl's (1999; Jordan, 2014) concept thresholds, it was possible to identify critical occurrence sand clarifying features belonging to the different mode of languages ${ }^{2}$. In this analysis we use the concept threshold for describing a critical occurrence when teachers appropriate a new mode of languages. This does not mean that they abandon the former mode but include a new mode in their repertoire.

As the categorization matrix elucidates the first threshold is crossed when teachers appropriate knowledge of, and start to use assessment concepts, jargon and technical terms. Likewise, the second threshold is crossed when the teachers are drawing causal connections, comprehend consequences and draw conclusions, or in other words contextualize the use of the assessment concepts.

Guided by the categorization matrix the first author in this second wave conducted deductive content analysis on the unit of analysis compiled in the first wave of analysis (Elo \& Kyngäs, 2008; Marshall \& Rossman, 2015). All of the data were considered for content and thereafter coded for correspondence with the mode of languages identified in the categorization matrix. Figure 3 gives three examples of how the deductive analysis was carried out, one example for each mode of languages.

${ }^{2}$ Glasl (1999; Jordan, 2014) uses the concept thresholds to illustrate actions that violate the standards applying how to behave against each other and how new norms are accepted as normal in different stages of a conflict escalation. 


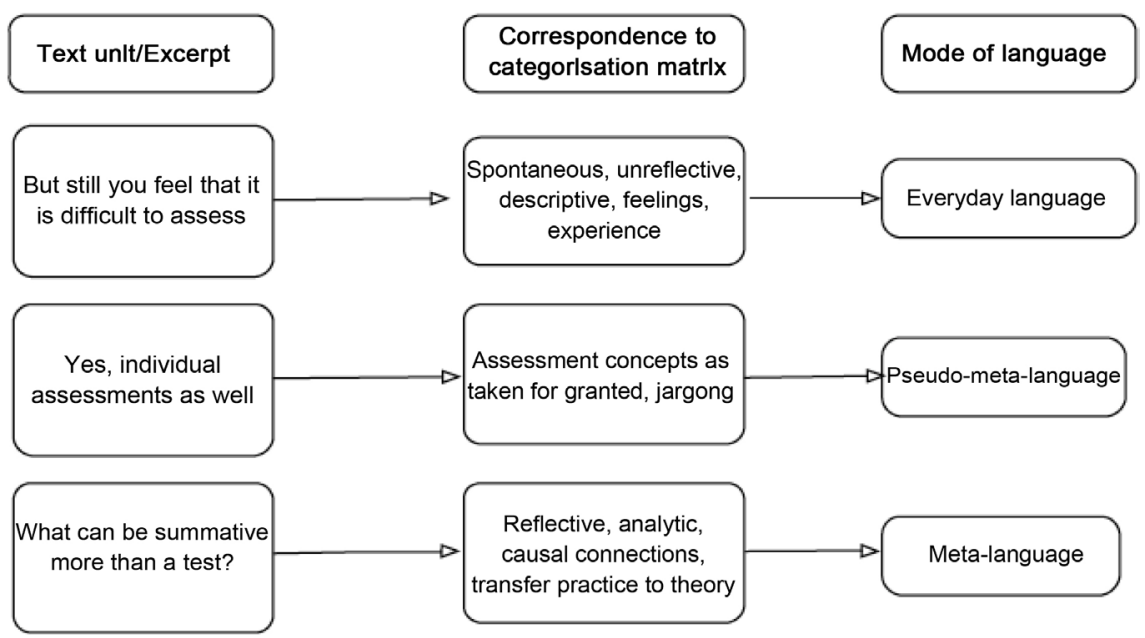

Figure 3. Deductive content analysis.

Each assessment text unit could include one or more modes of language codes and the codes varied in length. Although in this wave of the analysis the shorter codes were more common than the longer codes (see Table 2 for examples).

An inter-rater reliability test of the coding, concerning $14 \%$ of the unit of analysis, including both pre- and post-interviews, was performed by the second author using Cohen's Kappa, showing a high level of agreement $(\kappa=85.8$, Excel for Mac 14.7.3).

\subsubsection{Quantitative Analyses}

To be able to answer if and how teachers' use of the modes of language were influenced by them partaking in 1) a study about assessment in group work and 2) in an intervention in the form of a short educational session a quantitative analysis was necessary. Frequency analyses, regarding the distribution in different conditions were performed using and Chi ${ }^{2}$ test (Excel for Mac 14.7.3).

\subsection{Ethics and Quality}

The ethical principles provided by the British Psychological Society guidelines (BPS, 2014), which emphasise concern for participants' interest, have been applied throughout the study.

All participating teachers gave their written informed consent to be involved in the study. To enhance trustworthiness the entire research process was described in detail and the analysis process. The result presentation illustrates the link between the result and the empirical data (Elo \& Kyngäs, 2008; Graneheim \& Lundman, 2004). To increase the accuracy of the codes, the categorization matrix makes up for the somewhat vague description in Granström's model (Colnerud \& Granström, 2015) of the mode of languages (Hsieh \& Shannon, 2005). Additionally, facilitating transferability the context of the study, participants, and data collection are described thoroughly (Graneheim \& Lundman, 2004). 


\section{Results}

In keeping with the research questions for this paper, and the analysis described above, the results will be presented in both a qualitative and a quantitative way. The first part of the results focuses on describing how teachers talk about group work assessment using different modes of languages, while the second part focuses more on if there is any change in the language use before and after 1) partaking in the study per se or 2) participation in the study and in the intervention.

\subsection{How Teachers' Talk about Group Assessment}

The results show that all teachers, no matter if they participated in the intervention or not, use Granström's mode of languages but to a varying degree when talking about assessment in cooperative situations. The noteworthy discrepancy concerns the use of meta-language, i.e. some teachers barely used it while others used it more frequently. Another notable dissimilarity is that meta-language often consisted of longer coherent statements than everyday languages and pseudo-meta-language. In Table 2, excerpts illustrating different modes of language use are presented in pre- and post-interviews.

Table 2. Teachers' mode of language use before and after partaking in the study.

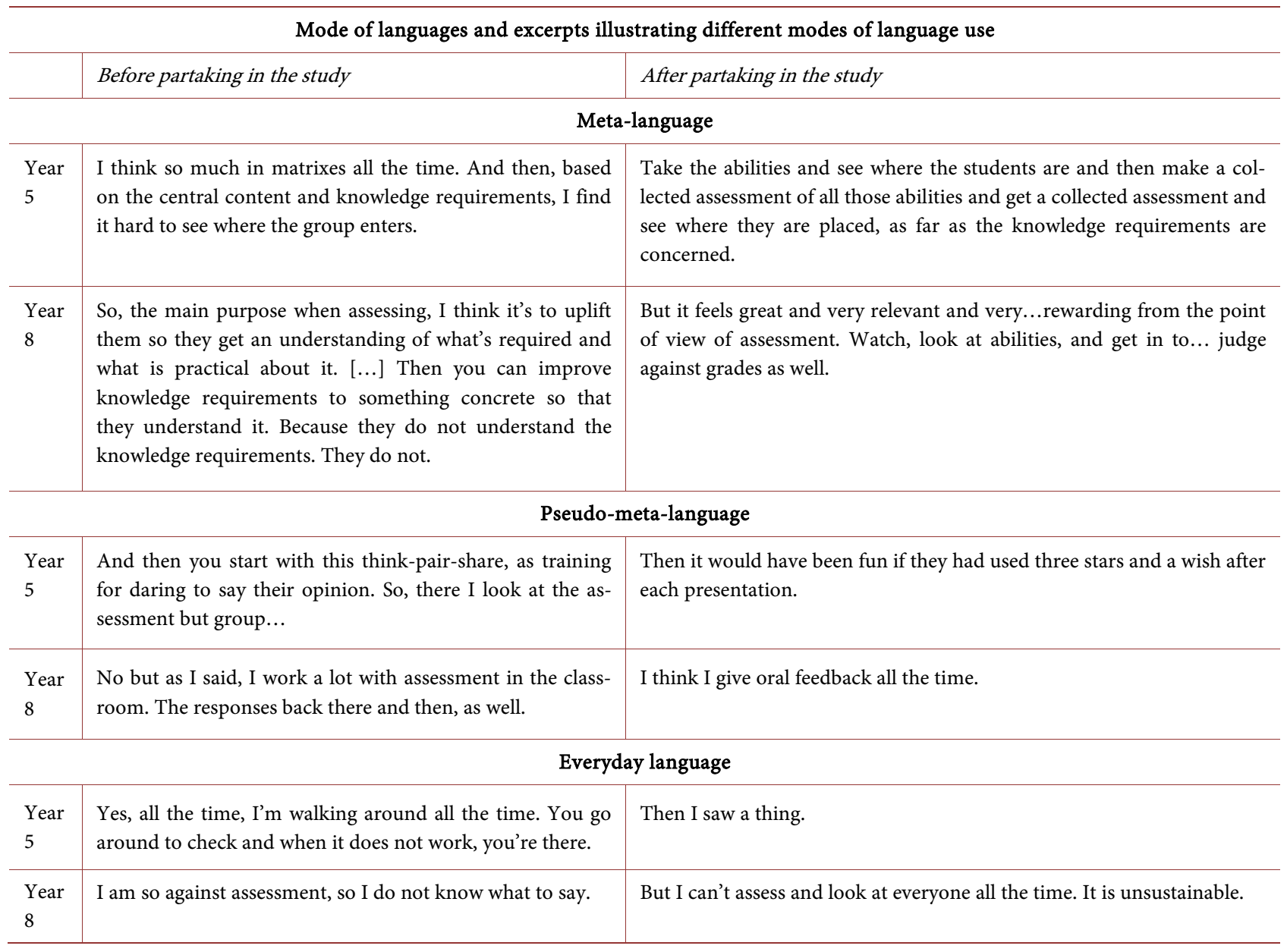


Further, the table illustrates how the teachers use the different mode of languages, that is to say what words they use and how they employ the words. In the analyses, we used thresholds (Glasl, 1999; Jordan, 2014), as critical occurrence for which mode of languages the teacher used. All teachers used everyday language when talking about group work assessment in the interviews. We argue that everyday languages, although commonly used by teachers, are necessary in some situations but not sufficiently enough in other situations. Teachers who know and use assessment concepts as well as jargon and technical terms, i.e. have crossed the threshold between everyday and pseudo-metalanguage, use these concepts in addition to everyday language in the interviews. Some of the teachers partaking in the interviews also made causal connections, talk about consequence, and draw conclusion in the conversation. Thus, they have crossed over the threshold between pseudo-meta- and metalanguage. Having access to meta-language does not signify that the teachers only use meta-language; on the other hand, these teachers use all three modes of Granström's prescribed use of languages. Therefore, we argue that this might be the sufficient way for teachers to talk about assessment in connection with group work. One of the teachers in the study problematises the use teachers using different modes of languages talking about a joint phenomenon, such as group work assessment.

If we begin to simplify and start using other and our own words as teachers, then we have no common language and then it becomes difficult to interpret, I think. So, we still have to find something in the school's world-a joint language where we can actually communicate and go forward. Now, I think we are talking past each other a little and it becomes difficult to interpret and a difficult world that we have in school today. Thus, I think it's more important to agree about something (Teacher Year 5).

As we can see in the quote, the teacher argues for the importance of a common assessment language.

\subsection{Changes before and after Partaking in the Study}

The second part of the results deals with if there is any change regarding mode of language use and if so, in what way. In other words, if partaking in the study or the study and the intervention have influenced the teachers' use of mode of languages when talking about assessment in cooperative situations. The results show that there are overall fewer statements about "assessment" before than after participating in the study. Further, most of the statements do not refer to assessment in general, but to group work assessment.

As shown in Table 3, 386 numbers of statements (i.e. identified text units) were categorized as statements about assessment. As already elaborated in the analysis, assessments were viewed in a holistic way, and there are variations in the statement length. Approximately $2 / 3$ of all statements that included any type 
of assessment came from post interviews. Or in other words, 2/3 of the statements about assessment were articulated in the post interviews. Some possible explanations may be 1) different questions in the interviews and/or 2) more extended statements in the before interviews than in the after interviews, or 3) that the teachers actually talked more about assessment after partaking in the study. After scrutinizing the data and the interview guides we advocate the last explanation is the most probable.

Table 3. Statements including assessment before and after participating in the study.

\begin{tabular}{llll}
\hline $\begin{array}{l}\text { Statements about } \\
\text { assessments }\end{array}$ & $\begin{array}{l}\text { Before participating } \\
\text { in the study }\end{array}$ & $\begin{array}{l}\text { After participating } \\
\text { in the study }\end{array}$ & $\begin{array}{l}\text { Total before and } \\
\text { after participating } \\
\text { in the study }\end{array}$ \\
\hline Number (percent) & $137(35 \%)$ & $249(65 \%)$ & $386(100 \%)$ \\
\hline
\end{tabular}

As seen in earlier studies, there is a possibility that the teachers unconsciously change their way of talking about assessment in group work because of the influence of just knowing they are participating in a study about assessment in group work, thereby changing their mode of using the languages. The possible change in how teachers talk before and after being included in the study due to the participation is elucidated in Table 4.

Table 4. Statements including different mode of language use before and after participating in the study.

\begin{tabular}{llll}
\hline Mode of languages & $\begin{array}{l}\text { Before } \\
\text { participating } \\
\text { in the study }(\mathrm{n}, \%)\end{array}$ & $\begin{array}{l}\text { After participating } \\
\text { in the study } \\
\text { (n, \%) }\end{array}$ & $\begin{array}{l}\text { Total before and } \\
\text { after participating } \\
\text { in the study (n, \%) }\end{array}$ \\
\hline Meta-language & $52(13 \%)$ & $97(21 \%)$ & $149(17 \%)$ \\
Pseudo-meta-language & $120(31 \%)$ & $114(25 \%)$ & $234(28 \%)$ \\
Everyday language & $219(56 \%)$ & $245(54 \%)$ & $464(55 \%)$ \\
Total & $391(100 \%)$ & $456(100 \%)$ & $847(100 \%)$ \\
\hline
\end{tabular}

$\mathrm{N}=$ number of statements, $\%=$ percent. Note: each statement/text unit including assessment before and after participating in the study (Table 3) could include one or more mode of languages statements (Table 4), which explains the difference in total numbers.

Table 4 presents the distribution of teachers' use of different modes of languages pre- and post-interviews. The pattern shown is different regarding the quantity of statements about assessment group work (see above and Figure 2). Here the result displays a pattern showing that teachers' use of meta-language increases while pseudo-meta-language and everyday language decrease, when comparing statements before and after interviews. Further, it is clear that teachers in general use everyday language in slightly more than half of the statements (55\%), 
while pseudo-meta-language is used just under one third of the statements $(28 \%)$ and that meta-language is used least (17\%). There is a significant difference between the mode of language teachers' use before and after partaking in the study about group work assessment $\left(\mathrm{Chi}^{2}=10.27 \mathrm{Df} 2 \mathrm{p}=0.0058\right.$; Excel for Mac 14.7.3). When interpreting this result it is important to recollect that only two of the eight teachers interviewed did not participate in the intervention. The teachers who participated in the intervention may be driving the results because they correspond to $75 \%$ of the participants included in this analysis. To get more information about cause and effect the next two analyses scrutinized if the intervention influenced the teachers or not.

\subsection{Changes before and after Partaking in the Study and in the Intervention}

Table 5 displays the distribution of teachers' use of different mode of languages when talking about group work assessment before partaking in the study and the intervention.

Table 5. Statements including different mode of language use before and after participating in the study and the intervention.

\begin{tabular}{llll}
\hline Mode of languages & $\begin{array}{l}\text { Before } \\
\text { participating in } \\
\text { the intervention } \\
(\mathrm{n}, \%)\end{array}$ & $\begin{array}{l}\text { After participating } \\
\text { in the intervention } \\
(\mathrm{n}, \%)\end{array}$ & $\begin{array}{l}\text { Total before and } \\
\text { after participating } \\
\text { in the intervention } \\
(\mathrm{n}, \%)\end{array}$ \\
\hline Meta-language & $36(13 \%)$ & $77(23 \%)$ & $113(18 \%)$ \\
Pseudo-meta-language & $84(30 \%)$ & $79(23 \%)$ & $163(26 \%)$ \\
Everyday language & $160(57 \%)$ & $186(54 \%)$ & $346(56 \%)$ \\
Total & $280(100 \%)$ & $342(100 \%)$ & $622(100 \%)$ \\
\hline
\end{tabular}

$\mathrm{n}=$ number of statements, $\%=$ percent.

Teachers' mode of language use follows the same pattern regarding quantity before and after statements on a general level, but also concerning the distribution of different levels. There is a significant difference between the mode of language teachers' use before and after partaking in the study and intervention concerning assessment in group work $\left(\mathrm{Chi}^{2}=10.91 \mathrm{Df} 2 \mathrm{p}=0.00427\right.$; Excel for Mac 14.7.3). In fact, the increased use of meta-language is slightly more evident in this analysis at the expense of the pseudo-meta-language. This suggests that teachers who have participated in the intervention have crossed the threshold between pseudo-meta-language and meta-language enhancing a causal connection, talking about consequence, and drawing conclusions in the after interviews.

The result concerning teachers' use of mode of languages after partaking in the study, but not the intervention is problematised next. 


\subsection{Changes before and after Partaking in the Study but Not in the Intervention}

Table 6 shows the frequency distribution of statements regarding the two teachers who did not partake in the intervention in the study ${ }^{3}$.

The third type of pattern is distinguished in this analysis based on two participant statements in before and after interviews talking about assessment. While use of meta-language and pseudo-meta-language follows the same pattern as before, although much weaker and not as distinct, the use of everyday language has changed. Still being used most frequently both during before and after interviews, but the quantity is almost equal in both measures. There is not a significant difference between the mode of language teachers' use before and after partaking in the study but not the intervention concerning assessment in group work $\left(\mathrm{Chi}^{2}=0.42 \mathrm{Df} 2 \mathrm{p}=0.81115\right.$; Excel for Mac 14.7.3).

Based on these results we argue that the intervention influenced the way teachers talk about assessment in group work. It is not enough just partaking in the study, but teachers who also participated in the intervention in the form of a short educational session developed their own way of talking about group work assessment the most. They not only gained knowledge of and started using new assessments concepts, but also made causal connections, acknowledged consequences, and drew conclusions.

Table 6. Statements including different mode of language use before and after participating in the study but not in the intervention.

\begin{tabular}{llll}
\hline Mode of languages & $\begin{array}{l}\text { Before } \\
\text { participating in } \\
\text { the study but not } \\
\text { intervention }\end{array}$ & $\begin{array}{l}\text { After participating } \\
\text { in the study but } \\
\text { not intervention }\end{array}$ & $\begin{array}{l}\text { Total before and } \\
\text { after participating } \\
\text { in the study but } \\
\text { not the } \\
\text { intervention }\end{array}$ \\
\hline Meta-language & $16(14 \%)$ & $20(17 \%)$ & $36(16 \%)$ \\
Pseudo-meta-language & $36(33 \%)$ & $35(31 \%)$ & $71(32 \%)$ \\
Everyday language & $59(53 \%)$ & $59(52 \%)$ & $118(52 \%)$ \\
Total & $111(100 \%)$ & $114(100 \%)$ & $225(100 \%)$ \\
\hline
\end{tabular}

$\mathrm{n}=$ number of statements, $\%=$ percent.

\section{Discussion}

Contrary to the trend in previous research on classroom dialogue we have focused on teacher-teacher talk, to our knowledge a neglected aspect related to talking situated in the classroom (e.g. Gillies, 2014, 2017; Howe, 2014; Mercer \& Dawes, 2014; Rojas-Drummond \& Mercer, 2003). Further, the dialogue taking place in the classroom is constantly developed through interaction and communication. Nevertheless, we argue that the languages and concepts used by the ${ }^{3}$ As mentioned before the teachers in the control group got the same intervention after the study was completed. 
teachers can be the result of a common professional language jointly developed through colleagues support in other situations. In keeping with that, we have chosen to focus on how teachers communicate and discuss their pedagogical practice, such as assessment in cooperative situations located outside the classroom, thus in this article in an interview situation. Previous research about group work assessment has revealed that teachers employ embryonic professional language and have problems verbalizing their pedagogical practice concerning group work assessment (Forslund Frykedal \& Hammar Chiriac, 2011, 2017; Gillies \& Boyle, 2010). We argue, supported by Colnerud \& Granström, (2015) that the importance of having access to a common professional language, theories and/or models concerning group work assessment cannot be neglected. Or, as one teacher in this study put it, "If I don't know how to assess or don't have the words describing how I assess, it's difficult to assess". Hence, once again confirming the gap between teachers' talk about assessment and collegial support for developing procedures surrounding group work assessment (Forslund Frykedal \& Hammar Chiriac, 2011, 2017), or the lack of common language. Several studies have called attention to the importance of teachers being given opportunities to develop their professional language (Colnerud \& Granström, 2015; Mercer, 2008, 2013; Rojas-Drummond \& Mercer, 2003), which this study has confirmed.

The aim of this article was to examine teachers' language repertoire when talking about group work assessment and if it is possible to influence the teachers discourse by means of a small education (cf. e.g. Ashman \& Gillies, 1997; Black, Harrison, Lee, Marshall, \& William, 2003; Gillies \& Ashman, 1996; Mercer, 2008; Mercer \& Sams, 2006), building on Granström’s model (Colnerud \& Granström, 2015), using Granström’s model (Colnerud \& Granström, 2015) describing three possible modes of language teachers may use: everyday, pseudo-meta- and meta-language was beneficial, but insufficient. One problem was the embryonic description of the different mode of languages, which enclosed questions regarding the characteristics and the significant dissimilarities between the different modes. During the operationalization of the model in order to compile a robust categorization matrix (Elo \& Kyngäs, 2008) it became obvious that we needed to develop the model further. With the support of Glasl's concept thresholds (Glasl, 1999; Jordan, 2014), we could identify critical occurrences and clarify features belonging to each mode of languages and thereby compile a robust categorization matrix. The threshold became important as they clearly define what knowledge the teacher must possess for the next mode of languages. Stepping over a threshold does not mean that the teachers abandon the former mode of language, but instead incorporate and expand their mode of language use in their repertoire. Developing and testing the categorizations matrix has elucidated the fact that the matrix could be a useful tool when interpreting and analysing teachers' talk about assessment in cooperative situations. The developed matrix thereby contributes theoretically and is a unique part of the results 
in this study, adding to previous research in the field of classroom dialogue.

The results expose that the teachers, no matter if they participated in the intervention or not, used Granstöm's mode of languages (Colnerud \& Granström, 2015) but to a varying degree when talking about assessment in cooperative situations. This implies that all teachers, at least once, have been employing meta-language. Thus, the model may be interpreted that teachers have access to all three modes of languages, but have the centre of gravity in one of the modes. Yet the results hold further implications. Despite having access to meta-language, this is not the common language used when the teacher are talking to, if not a colleague, an equivalent fellow teacher acting as an interviewer where meta-language would be applicable language. Hence, a situation where teachers could use a common professional language and/or even an opportunity for collegial support (Ashman \& Gillies, 1997; Black et al, 2003; Colnerud \& Granström, 2015; Gillies \& Ashman, 1996; Mercer, 2008, 2013; Rojas-Drummond \& Mercer, 2003). This raises the question if some teachers just employ meta-language quite coincidently and do not really have access to a meta-language. Even though the findings imply that this is the case, this study cannot answer that question.

A core result in this study, adding to previous research on both classroom dialogue and group work assessment, is that the intervention has influenced the teachers talking about group work assessment. The teachers talk more about group work assessment in the post interviews and use more meta-language at the expense of pseudo-meta-language after they participated in the intervention. Thus, we argue that a short education can produce good effects, confirming previous research claiming the importance for teachers to have possibilities to develop their communication skills by education or/and intervention (Mercer, 2008, 2013; Rojas-Drummond \& Mercer, 2003). In the intervention in this study the teachers had, for two days, an opportunity to develop their language and knowledge regarding group work assessment by education and collegial support. In other words, by communicating with colleagues, learning about different assessment practices as well as concept development and by increasing the comprehension together develops a common professional language.

The findings in the current study contribute new and unique contributions by 1) presenting a new theoretical model; 2) emphasising teachers' language in research related to classroom dialogue; 3 ) the usefulness of a small intervention and 4) new insights concerning group work assessments, thus providing both theoretical and scientific contributions.

\section{Limitation}

A general limitation in this study and, especially when interpreting the quantitative results, is the low number of participants; only eight teachers were interviewed. It is worth noting that only two teachers were included in the control group, i.e. did not participate in the intervention. We argue that the rationale for focusing on a very small group of participants in this particular study was that 
they are equivalent to the total group of teachers interviewed. Ideally, we would have included more informants "but that does not justify ignoring the information we could obtain" (Mercer, 2008: p. 47) from the participating group of teachers. Despite this, we argue that the findings clearly show that the participating effect cannot explain the change in teachers' use of language modes when talking about the group work assessment. The intervention is crucial for teachers to develop and expand their mode of language use, thus promoting the employment of a common professional language when talking about group work assessments. Although, this study has led to some interesting insights there is a need for more attention in further research, preferably a lager intervention study including more participants.

\section{Conclusion}

Assessment fitting cooperative situations is a highly relevant, but a challenging factor for teachers when organising group work in an educational setting. One of the teachers' challenges confirmed once again in this study seems to be the lack of a common professional language with useful terminology, models, and concepts when talking about group work assessment. For teachers to be able to talk about and develop strategies for assessment fitting cooperative situations they need to "speak the same professional language". In this study, we have elucidated that teachers used different modes of languages when talking about group work assessment. Nevertheless, the teachers mostly employ a general level of discourse and use a restricted repertoire in their talk. A core finding in this study is that an intervention in the form of a short education can influence teachers' languages use in a positive way. By participating in the intervention, the teachers' developed and expanded their mode of languages use and include new modes into their repertoire. We argue that the use of languages is an important springboard for developing assessment strategies for cooperative situations and that it is possible with a small effort to influence teachers' use of languages in a profitable way, thus promoting the use of a common professional language about group work assessment. The matrix developed and tested in this study could be a useful tool both regarding theory development and from a user's perspective to help teachers develop a common assessment language.

In further research, it would be interesting to explore and problematise teachers' academic talk by looking at the content in teachers' statements when discussing assessment in group work.

\section{Funding}

The author(s) discloses that this work was supported by the Swedish Research Council, Grant number: VR dnr 721 2012-5476.

\section{Disclosure Statement}

The authors declare no potential conflict of interest with respect to the research, 
authorship and/or publication of this article.

\section{Ethical}

The study was approved by the regional Research and Ethics Committee at Linköping University, Sweden (Dnr 2013/401-31 \& Dnr 2014/134-32).

\section{Funding Declaration}

This work was supported by the Swedish Research Council under Grant number: VR dnr 721 2012-5476.

\section{Conflicts of Interest}

The authors declare no conflicts of interest regarding the publication of this paper.

\section{References}

Ashman, A. F., \& Gillies, R. M. (1997). Children's Co-Operative Behavior and Interactions in Trained and Untrained Work Groups in Regular Classrooms. Journal of School Psychology, 35, 261-279. https://doi.org/10.1016/S0022-4405(97)00007-1

Black, P., \& Wiliam, D. (1998a). Assessment and Classroom Learning. Assessment in Education: Principles, Policy \& Practice, 5, 7-74. https://doi.org/10.1080/0969595980050102

Black, P., \& Wiliam, D. (1998b). Inside the Black Box: Raising Standards through Classroom Assessment. Phi Delta Kappan, 92, 81-90. https://doi.org/10.1177/003172171009200119

Black, P., Harrison, C., Lee, C., Marshall, B., \& Wiliam, D. (2003). Assessment for Learning: Putting It into Practice. Buckingham: Open University Press.

British Psychological Society, BPS (2014). Code of Human Research Ethics. https://www.bps.org.uk/news-and-policy/bps-code-human-research-ethics-2nd-editio $\underline{\mathrm{n}-2014}$

Colnerud, G., \& Granström, K. (2015). Respect for the Teaching Profession. About the Teacher's Professional Language and Professional Ethics. Stockholm: Liber AB.

Elo, S., \& Kyngäs, H. (2008). The Qualitative Content Analysis Process. Journal of Advanced Nursing, 62, 107-115. https://doi.org/10.1111/j.1365-2648.2007.04569.x

Forsell, J., Forslund Frykedal, K., \& Hammar Chiriac, E. (2019). Review of Group Work Assessment-Assessment of Social Skills at Group Level. Small Group Research.

Forslund Frykedal, K., \& Hammar Chiriac, E. (2011). Assessment of Students' Learning When Working in Groups. Educational Research, 53, 331-345. https://doi.org/10.1080/00131881.2011.598661

Forslund Frykedal, K., \& Hammar Chiriac, E. (2017). To Make the Unknown Known: Assessment in Group Work among Students. Journal of Educational Research, 2, 149-162.

Forslund Frykedal, K., \& Hammar Chiriac, E. (2018). Student Collaboration in Group Work: Inclusion as Participation. International Journal of Disability, Development and Education, 65, 183-198. https://doi.org/10.1080/1034912X.2017.1363381

Gillies, R. M. (2014). Developments in Cooperative Learning: Review of Research. Anales de Psicologia, 30, 792-801. https://doi.org/10.6018/analesps.30.3.201191 
Gillies, R. M. (2016). Cooperative Learning: Review of Research and Practice. Australian Journal of Teacher Education, 41, 39-54. https://doi.org/10.14221/ajte.2016v41n3.3

Gillies, R. M. (2017). Promoting Academically Productive Student Dialog during Collaborative Learning. International Journal of Education Research, 97, 1-10. https://doi.org/10.1016/j.compedu.2015.07.014

Gillies, R. M., \& Ashman, A. F. (1996). Teaching Collaborative Skills to Primary School Children in Classroom-Based Group Work. Learning and Instruction, 6, 187-200. https://doi.org/10.1016/0959-4752(96)00002-3

Gillies, R. M., \& Boyle, M. (2010). Teachers' Reflections on Cooperative Learning: Issues of Implementation. Teaching and Teacher Education, 26, 933-940. https://doi.org/10.1016/j.tate.2009.10.034

Gillies, R., \& Khan, A. (2008). The Effects of Teacher Discourse on Student's Discourse, Problem-Solving and Reasoning during Cooperative Learning. International Journal of Educational Research, 47, 323-340. https://doi.org/10.1016/j.ijer.2008.06.001

Gillies, R., \& Khan, A. (2009). Promoting Reasoned Argumentation, Problem-Solving and Learning during Small-Group Work. Cambridge Journal of Education, 39, 7-27. https://doi.org/10.1080/03057640802701945

Glasl, F. (1999). Confronting Conflict. A First-Aid Kit for Handling Conflicts. Stroud: Hawthorne Press.

Graneheim, U. H., \& Lundman, B. (2004). Qualitative Content Analysis in Nursing Research: Concepts, Procedures and Measures to Achieve Trustworthiness. Nurse Education Today, 24, 105-112. https://doi.org/10.1016/j.nedt.2003.10.001

Hammar Chiriac, E., \& Forslund Frykedal, K. (2019). Assessment in Group WorkMethod and Implementation of an Intervention Study.

Howe, C. (2014). Optimizing Small Group Discourse in the Classrooms: Effective Practice and Theoretical Constraints. International Journal of Educational Research, 63, 107-115. https://doi.org/10.1016/j.ijer.2013.03.011

Howe, C., Tolmie, A., Thurston, A., Topping, K., Christie, D., \& Livingston, K. (2007). Group Work in Elementary Science: Towards Organizational Principles for Supporting Pupil Learning. Learning and Instruction, 17, 549-563.

https://doi.org/10.1016/j.learninstruc.2007.09.004

Hsieh, H., \& Shannon, S. E. (2005). Three Approaches to Qualitative Content Analysis. Qualitative Health Research, 15, 1277-1288. https://doi.org/10.1177/1049732305276687

Johnson, D. W., \& Johnson, R. T. (1994). Learning Together and Alone (4th ed.). Boston: Allyn \& Bacon.

Johnson, D. W., \& Johnson, R. T. (2002). Learning Together and Alone: Overview and Meta-Analysis. Asia Pacific Journal of Education, 22, 995-1005. https://doi.org/10.1080/0218879020220110

Johnson, D. W., \& Johnson, R. T. (2004). Assessing Students in Groups: Promoting Group Responsibility and Individual Accountability. Thousand Oaks, CA: SAGE.

Johnson, D., Maruyama, G., Johnson, R., Nelson, D., \& Skon, L. (1981). Effects of Cooperative, Competitive, and Individualistic Goal Structures on Achievement: A Meta-Analysis. Psychological Bulletin, 89, 47-62.

Jordan, T. (2014). Handbook in Conflict Management for Organizational Consultants and Personnel Specialists. Sävedalen: Perspectus Kommunikation AB.

Keddie, N. (1984). Classroom Knowledge. In A. Hargreaves, \& P. Woods (Eds.), Classrooms and Staffrooms. The Sociology of Teachers and Teaching (pp. 108-122). Milton Keynes: Open University Press. 
Kuisma, R. (2007). Portfolio Assessment of and Undergraduate Group Project. Assessment and Evaluation in Higher Education, 32, 557-569. https://doi.org/10.1080/02602930601116904

Marshall, C., \& Rossman, G. B. (2015). Designing Qualitative Research. London: SAGE Publication.

Mercer, N. (2008). The Seeds of Time: Why Classroom Dialogue Needs a Temporal Analysis. Journal of the Learning Sciences, 17, 33-59. https://doi.org/10.1080/10508400701793182

Mercer, N. (2013). The Social Brain, Language, and Goal-Directed Collective Thinking: A Social Conception of Cognition and Its Implications for Understanding How We Think, Teach and Learn. Educational Psychologist, 48, 148-168. https://doi.org/10.1080/00461520.2013.804394

Mercer, N., \& Dawes, L. (2014). The Study of Talk between Teachers and Students, from the 1970s until the 2010s. Oxford Review of Education, 40, 439-445. https://doi.org/10.1080/03054985.2014.934087

Mercer, N., \& Howe, C. (2012). Explaining the Dialogic Process of Teaching and Learning: The Value and Potential of Sociocultural Theory. Learning, Culture and Social Interaction, 1, 12-21. https://doi.org/10.1016/j.lcsi.2012.03.001

Mercer, N., \& Sams, C. (2006). Teaching Children How to Use Language to Solve Maths Problems. Language and Education, 20, 507-528. https://doi.org/10.2167/le678.0

Mercer, N., Wegerif, R., \& Dawes, L. (1999). Children's Talk and the Development of Reasoning in the Classroom. British Educational Research Journal, 25, 95-111. https://doi.org/10.1080/0141192990250107

Michaels, S., \& O’Connor, C. (2015). Conceptualizing Talk Moves as Tools: Professional Development Approaches for Academically Productive Discussions. In L. B. Resnick, C. Asterhan, \& S. N. Clarke (Eds.), Socializing Intelligence through Talk and Dialogue (pp. 333-347). Washington DC: AERA. https://doi.org/10.3102/978-0-935302-43-1_27

Murray, J. A., \& Boyd, S. (2015). A Preliminary Evaluation of Using WebPA for Online Peer Assessment of Collaborative Performance by Groups of Online Distance Learners. International Journal of E-Learning and Distance Education, 2, 112-124.

Rojas-Drummond, S., \& Mercer, N. (2003). Scaffolding the Development of Effective Collaboration and Learning. International Journal of Educational Research, 39, 99-111. https://doi.org/10.1016/S0883-0355(03)00075-2

Roseth, C., Johnson, D., \& Johnson, R. (2008). Promoting Early Adolescents' Achievement and Peer Relationships: The Effects of Cooperative, Competitive, and Individualistic Goal Structures. Psychological Bulletin, 134, 223-246.

https://doi.org/10.1037/0033-2909.134.2.223

Slavin, R. E. (1989). Cooperative Learning and Student Achievement. In R. Slavin (Ed.), School and Classroom Organization (pp. 129-156). New Jersey: Lawrence Erlbaum.

Slavin, R. E. (1996). Research on Cooperative Learning and Achievement: What We Know, What We Need to Know. Contemporary Educational Psychology, 21, 43-69. https://doi.org/10.1006/ceps.1996.0004

van Aalst, J. (2013). Assessment in Collaborative Learning. In C. E. Hmelo-Silver, C. A. Chinn, C. K. K. Chan, \& A. O’Donell (Eds.), The International Handbook of Collaborative Learning (pp. 280-296). London: Routledge.

Webb, N. (2009). The Teacher's Role in Promoting Collaborative Dialogue in the Classroom. British Journal of Educational Psychology, 79, 1-28.

https://doi.org/10.1348/000709908X380772 
Webb, N., \& Mastergeorge, A. (2003). Promoting Effective Helping in Peer-Directed Groups. International Journal of Educational Research, 39, 73-97. https://doi.org/10.1016/S0883-0355(03)00074-0

Webb, N., Franke, M., Ing, M., Chan, A., De, T., \& Freund, D. (2008). The Role of Teacher Instructional Practices in Student Collaboration. Contemporary Educational Psychology, 33, 360-381. https://doi.org/10.1016/j.cedpsych.2008.05.003

Webb, N., Franke, M., Ing, M., Turrou, A., \& Johnson, N. (2015). Student Participation, Teacher Instructional Practices, and the Developmental of Mathematical Understanding in the Elementary Classroom. In R. Gillies (Ed.), Collaborative Learning: Developments in Research and Practice (pp. 47-68). Hauppauge, NY: Nova Science.

Webb, N., Franke, M., Ing, M., Wong, J., Fernandez, C., Shin, N. et al. (2014). Engaging with Others' Mathematical Ideas: Interrelationships among Student Participation, Teachers' Instructional Practices, and Learning. International Journal of Educational Research, 63, 79-93. https://doi.org/10.1016/j.ijer.2013.02.001

Wiliam, D. (2009). Assessment for Learning — Why, What and How? London: University of London, Institute of Education.

Wiliam, D. (2011). What Is Assessment for Learning? Studies in Educational Evaluation, 37, 3-14. https://doi.org/10.1016/j.stueduc.2011.03.001

Wiliam, D., \& Thompson, M. (2007). Integrating Assessment with Learning. What Will It Take to Make It Work? In C. A. Dwyer (Ed.), The Future of Assessment (pp. 53-82).New York: Routledge. https://doi.org/10.4324/9781315086545-3

Zhang, B., Johnston, L., \& Bagci Kilic, G. (2008). Assessing the Reliability of Self and Peer Rating in Student Group Work. Assessment \& Evaluation in Higher Education, 33, 329-340. https://doi.org/10.1080/02602930701293181 


\section{Appendix 1}

\section{Interview Guide (before)}

1) Introduction, background? (age, gender, education, years as a teacher, years as a teacher in this class, single teacher in the class/several teachers in the class).

2) Tell us about your experiences of using group work as a pedagogical method in the class room? (e.g. organisation, task, group formation, group contract).

3) What are your experiences of how group work function? (e.g. well-functioning or not, why, group work skills).

4) Tell us about your experiences of performing assessments of students' knowledge and ability when they are working in groups? (e.g. purpose, level, what, how, who).

5) Tell us about the students' perceptions of (attitude to) working in group? (e.g. good/bad, why).

6) Tell us about the students' perceptions of (attitude to) being assessed when working in group? (e.g. good/bad, why).

7) Is there anything more that you would like to tell us that we have forgotten to ask about?

\section{Interview Guide (after)}

1) If you think back on your experience of using group work as a pedagogical method before the project and compare it with your experience of using group work as a pedagogical method after the project. Tell us about the changes (if any) regarding 1) the idea of (attitude to) using group work as a pedagogical method; 2) knowledge about group work as a pedagogical method; 3) putting group work in practice (e.g. organisation, task, group formation, group contract).

2) What are your experiences of how the group work function during the project? (e.g. well-functioning or not, why, group work skills).

3) If you think back on your experience of performing assessment during group work before project and compare it with your experiences of performing assessment during group work after the project. Tell us about the changes (if any) regarding 1) the idea of (attitude to) group work assessment; 2) knowledge of group work assessment; 3 ) group work assessment in practice (e.g. purpose, level, what, how, who).

4) Tell us about the students' perceptions of (attitude to) working in group? (e.g. good/bad, why).

5) Tell us about the students' perceptions of (attitude to) being assessed when working in group? (e.g. good/bad, why).

6) Is there anything more that you would like to tell us that we have forgotten to ask about? 